\title{
Gender Domination and Domestic Violence in Nigerian Video Films: A Paradigmatic Appraisal
}

\author{
Tracie Chima Utoh-Ezeajugh \& Ekene Euphemia Anijah \\ http://dx.doi./org/10.4314/ujah.v18i3.1
}

\begin{abstract}
This paper examines the symmetry between domestic violence and gender domination by $x$-raying some of the issues and challenges that generate domestic violence. Using two video Films produced in the Nigerian Film Industry as case studies, the work argues that gender based violence is not limited to the female gender because, beyond physical demonstration of violence against women, men face psychological violence in the pursuance of their patriarchal ideologies. The study employed the interpretative approach to content analysis within the qualitative research methodology in undertaking a critical analysis of the films. Video Compact Discs (VCDs) and Digital Video Discs (DVDs) and related literatures in film, and feminist theory as well as postulations on domestic violence and Gender domination are used for data analysis. The findings reveal that domestic violence is not limited to the feminine gender. Beyond physical demonstration of violence against women, men also face psychological violence in varied degrees. The investigation reveals that gender domination generates violence among men and women because groups with the intent to dominate and suppress one another in a relationship cause marital crises. A strive towards mutual co-existence is therefore advocated.
\end{abstract}




\section{Introduction}

Domestic Violence and Gender domination have received some prominence in academic and social discourse in recent times, thus, different scholars and authorities have attempted to give them definitions and concepts. In his views, Abayomi argues that

Domestic violence against women is an issue of global concern that is gaining more and more prominence. It transcends national, cultural, racial and class boundaries. It is a social malady that is threatening the stable and balanced psychological development of children in the Nigerian society. Children raised in violent homes are known to imbibe violent tendencies as they grow up.(8)

In the same vein, Aihie posits that "domestic violence is the intentional and persistent abuse of anyone in the home in a way that causes pain, distress or injury."(1) It refers to "any abusive treatment of one family member by another", thus violating the law of basic human rights. "It includes battering of intimate partners and others, sexual abuse of children, marital rape and traditional practices that are harmful to the partner" (1). Female genital mutilation is also a form of domestic violence. Domestic violence occurs globally from all social, racial, economic, educational and religious backgrounds."'(Dahlberg and Krug, 2, UNICEF, 5).This implies that domestic violence occurs at all levels of social class, educational and religious backgrounds. And this turbulent issue does not apply to women alone but also to men. This is affirmed in Animasaun, K. and Animasaun, A. who posit that "studies abound that show that men are also victims of Gender Based Violence (GBV)"(62). Gender Based Violence is therefore not 
gender or location specific. Gender based violence is not limited to the feminine group. Beyond physical demonstration of violence against women, men face psychological violence which results from the conflict occasioned by feminist ideologies. This has been showcased in several Nollywood films. Of course, this will be discussed using the selected Nigerian films to analyze and determine the perpetration, level, forms and the focus of domestic violence in Nigerian homes and in the process, highlighting the causes of this domestic violence.

In order to expose and address issues of domestic violence and gender domination, the Nigerian film industry generally known as Nollywood has through several movies showcased measures of preventing gender based violence in marital homes. The industry, has emphasized morality and cultures as instruments of lighting the menace of violence in marital homes. The makers of the films have laid emphasis on contemporary realities which many Nigerians can relate to, to show that movies with household violence and gender domination undertone are used to educate and entertain its audience and society at large on how intimate partners can manage crisis in their marital relationships.

Thus, Nigerian filmmakers often make movies, with themes that are very educative and entertain bearing in mind that films are essential means of societal transformation; the film medium readily volunteers itself as a platform for the investigation of human conflicts that recur in various societies. Unarguably, the operators of the Nigerian video film industry - Nollywood - have assiduously worked to adjust certain social orientations through their portrayal in video films of the social, political, economic and cultural specifics that define the existence of the Nigerian people. Hence, films serve as a catalyst for social change. The Nigerian film industry has continued to align with social realities in making 
their stories more effective for social transformation. It is against this background that this study seeks to evaluate gender symmetry in intimate partner use of violence in a relationship. The following Nollywood films are used for analysis: $M r \&$ Mrs (2011), Damage (2013).

There is no gainsaying the fact that movies portray a lot of the ills of the society and some of these ills include violence which may or may not have adverse effects on the society at large. Some of these violent issues portrayed in Nigerian video films include domestic violence, divorce, murder, nudity, rape, molestation and assault. Thus, films portray scenes with the above listed thematic issues with the intent to show that they are immoral acts. To this effect, filmmakers use the film medium to $\mathrm{x}$-ray domestic violent themes in order to change the landscape of cultural beliefs. Films with Domestic violence and Gender domination as thematic issues show what families, marriages or couples experience. Yet, after husbands and wives must have watched these films described above, they do not see reasons to exercise patience, tolerance and develop the culture of having good understanding of their partners in their relationships, and marriages.

Each group would not like to be suppressed by the other and when one amongst the two groups dominates the other, both feel the psychological effect, at some point it leads to revolt in a violent way. Moreover, the worrisome aspect of some Nollywood films is that some of them portray violent images with the motive of discouraging the negative domestic violence tendencies acted on screen, but the manner in which the filmmakers project these images sometimes have adverse effects on their audience. Domestic violence appears to be rampant in the Nigerian society. It is a problem that has showed itself in many areas of the people's lives. Despite the fact that many studies report that violence is 
being perpetrated by men against women other studies suggest that domestic violence is carried out by both men and women alike. Some observers feel that Nollywood films are contributing to this moral decadence in addition to the early exposure of youths to the electronic media. In that wise, many critics have condemned the kind of films shown in Africa today. According to Selima Rahman, '... if not checked soon, we will be faced with complete moral decadence (5). Therefore this study interrogates the use of violence to claim dominance in domestic contexts especially as it is given exposition in video films.

\section{Gender Issues in Nigerian Video Films}

In African societies domestic violence and gender domination are hinged on male domination over the female folk, which has generated unending controversies. For the women, this undermines the whole idea of feminism which preaches egalitarianism or equality of the sexes. In the words of Julie Umukoro \& Okwuowulu, C.,

Nollywood filmmakers ...it has been noted, attempt to replicate exactly, in finite terms, visual text culled from social reality; reinforcing thus the vision of gender imbalance and to the chagrin of feminist crusaders who opposed such (225).

Thus, Nollywood's presentation of stories in a video-film medium creates its assertiveness based on the narrative form which makes the audience witnesses of the actions going on in the visual experience. The film narrative with themes of gender domination and domestic violence tend to replicate social realities in this 
present dispensation which tends to correct the imbalance. These film narratives interestingly reflect strong cultural influences on gender and war among man and woman especially in marriages. Okoronkwo and Nwankwo buttress this point when they opine that creative input in these film narratives are being influenced by culture.(105) Thus, the images presented are mostly present situations and with motivational teachings that stimulate social change. Every film story has a motive which sympathizes with or persecutes a person and a situation in order to uphold a certain moral virtue.

Nollywood, in the words of Uwah has significantly become involved in the process of Africa's self-reflection and identity construction by means of its cultural perspectives and some ideological point of view. In this view, Kunzler asserts that Nollywood is "an industry that has developed out of context related to domestic and international cultural economic and political environments" (10). These elements of cultural issues are seen in films with themes such as Marriage Breakdown, Domestic Violence, Divorce to mention but a few. In a study of twelve films undertaken by Ogundipe, she observes that,

Male dominance is apparent in all twelve films examined, although more heavily so in Saworoide, Agogo Eewo, and Oluwa N'ileset in traditional rural settings. But even in urban situations like in Power of Love and comical Ukwa, Stupid, Atinga and others, the men have upper hand and take all the decisions. Sites of patriarchy include domestic work, paid work, male violence, sexuality and cultural institutions like the levirate and widowhood...( (95) 
The above expresses that many Nollywood films have gender undertones. Accordingly, Shaka and Uchendu maintain:

we conjectured that the recurrent and consistent negative portrayal of Nigerian women in Nollywood could be an attempt to justify and continue to perpetrate some gruesome traditions of trial by ordeal which women are subjected to at the demise of their husbands as a way of proving their innocence. Film scholars and critics need to rise up and cry out against this trend to save the Nigerian woman from further character assassination and misrepresentation locally and internationally... (14)

In the same vein, Oloruntoba-Oju reiterates that, "with Nollywood, the representation of sex and the expression of sexuality in general and female agency in particular attain a degree of orchestration never before witnessed in Nigerian cultural productions." (6) The extreme popularity of gender drama, i.e. the dramatic representation of sex-gender conflicts at various levels, can only be explained by the fact that gender-based conflicts account for a considerable amount of real life experience from childhood to adulthood. Viewers perhaps hope to glean some message for their own chequered encounters from these dramatic conflicts and their resolutions as relayed on the video screen." Thus, several films that addressed either in full or in passing, the question of gender domination and domestic violence with the view of providing suggestive solutions to such ill acts.

Mr \&Mrs is a film that represents the conflict and struggles of people in marriage. It portrays Susan's experience with husband Kenneth and how they were able to resolve issues that cropped up in their marriage. While they were having challenges, it was 
glaring that the husband Kenneth was maltreating and dominating the wife but at some point Susan got fed up and this resulted in the two fighting, beating and hitting each other with hard objects. She (Susan) had to seek for solution to save her marriage and restore her image in the family. Thus, Nollywood filmmakers strive to portray images that showcase these marital crises with scenes of violence with the intent to show its psychological experience on both parties and proffer possible solutions to some marital problems. The understanding of these images portrayed depends on how a particular audience perceived them. Another film 'New Horizon' talks about four women (Kate Henshaw, Rita Dominic, Uche Jombo, and Funke Akindele) who triumphed over domestic abuse. They met in a self-help group where they engaged in offering their shoulders for others to lean on. Another film, 'Crazy Love' is a film by Tamar Aid Foundation, which talks about violence in intimate relationships and portrays the possibility of people losing their lives through the practice of violence at home.

Social learning theory encompasses both imitation and identification to show how people learn through observation in their environment. Child Welfare Information Gateway (8) citing Brown and Bzostek, on the impact of domestic violence on children says that studies have shown that, "children in families experiencing domestic violence are more likely than other children to exhibit aggressive and antisocial behavior and males exposed to domestic violence as children are more likely to engage in domestic violence as adults". On the other hand, Oloruntoba-Oju, T. posits that, "Nollywood is essentially a message medium, almost wholly devoted to passing on a message, with few ambivalences in the ideological orientation or moral inclination of the productions" (7). The "moral" is frequently rendered explicit 
through the dramatic/filmic process of exposition. Any ambivalent rendition may be evidence of conflict in the orientation of members of the production crew, especially script writers, screen-writers, producers and directors and these roles are sometimes combined in individuals in Nollywood, thus, sometimes generating an internal conflict of passions and roles. In general, sex-gender drama activates gendered empathy from Nigerian film audiences. In a different context Onookome observes aptly that the Nigerian "home video films" reflect "the flux of identities and contestatory moralities" (Onookome, 68). Audiences participate actively albeit vicariously in the process of contestation. The phenomenon generates controversy; the market expands."Thus, Ogundipe states that, "family life is historically and culturally specific. (98). Ogundipe further submits that,

Although considerable literature is available on gender, discussion of the topic gender is still contentious, conflicting and somewhat confusing. There are many perspectives and approaches to the subject. Clatterbaugh's eight perspectives on gender which include the moral, pro-feminist, men's rights, mythopoesis, socialist, homosexual-male, African American, and evangelistical-Christian, are too involved and masculinist. (96).

In another vein, Oloruntoba-Oju, T. posits that

Films exhibited in the foregoing demonstration is a deliberate orchestration of the interplay of sex and power in an African context, the correlation of sexual agency with power and dominance, and the complex manifestation of gendered contest at various levels in domestic and public spheres. Admittedly, some of the filmic representations of this phenomenon may be quite 
banal. Also, the resolution of conflict in the films (including those by women script writers) tends to echo gender stereotypes... (24)

The society or social structure that we exist in is one that encourages a patriarchal hegemonic system and as such, this reflects upon how people's views are shaped or constructed. Linda Nochlin maintains that one of the key rationales of patriarchal ideology is to mask the power relationships that constitute society in such a manner as to appear natural or normal and eternally true. (Linda Nochlin, 1). Under such power relations, women are educated to recognize and internalize those restrictions as the norm, and as is to be expected or anticipated (Ann Kaplan, 36). Over the years, some Nollywood films have reflected these varied gender ideological leanings.

\section{Research Methodology and Theoretical Framework}

The study employs the qualitative research methodology in undertaking a critical assessment of the selected films. The strategies used in undertaking a gender reading and assessment of the films include typologies and metaphors. The paper employs the interpretative approach to content analysis designed to address how domestic violence is represented and how gender domination generates violence among men (husbands) and women (wives) in Nigerian video films. The focus is on the selected video films which are Ikechukwu Onyeka's Mr and Mrs and Moses Inwang's Damage.

The theoretical framework for this research is based on 'learned helplessness' and 'power and control wheel' Theories. These theories offer methodologies for the evaluation of the text and are based on the principles of the functionality of art. The 
reason is to attempt a critical analysis of how domestic violence and gender domination are portrayed in the film narratives in relation to the context of usage. A number of theoretical constructs and research underpin the current study, such as Learned Helplessness Theory, Social Learning Theory, Power and Control Wheel theory. Learned Helplessness Theory, propounded by Lenore Walker, a psychologist in the United States, who studied the behaviour of women who stay in violent relationships. Walker hypothesized that women stay in abusive relationships because constant abuse strips them of the will to leave. The learned helplessness theory, however, did not account for the fact that there are many social, economic and cultural reasons a woman might chose to stay in an abusive relationship. Women often have very rational reasons for staying, they may fear retaliation against themselves or their children, or they may not be able to financially support themselves or their children. They may be ostracized by their family and community if they leave. Further, the learned helplessness theory is inconsistent with the fact that women surviving in abusive relationships attempt to leave many times and routinely act in very conscious ways to try to minimize the abuse directed at them and to protect their children.

Social Learning Theory refers to Family violence which arises due to many contextual and situational factors. Contextual factors include individual/couple characteristics, stress, violence in the family, or an aggressive personality. Situational factors include substance abuse and financial difficulties. Social learning theory also extends these factors onto the influence on children growing up within a combination of these external forces. Social learning theory is one of the most popular explanatory perspectives in the marital violence literature. Often conceptualized as the "cycle of violence" or "intergenerational transmission theory" 
when applied to the family, the theory states that people model behavior that they have been exposed to as children. Violence is learned through role models provided by the family (parents, siblings, relatives, and boyfriends/girlfriends), either directly or indirectly (such as witnessing violence), is reinforced in childhood, and continues in adulthood as a coping response to stress or as a method of conflict resolution (Bandura). In the words of HydeNolan and Juliao "Social Learning Theory maintains that individuals learn social behaviours by observing and imitating other people". Imitation of models is an important element in how children learn. Transmission of violent behavior occurs through processes of modeling, failure to learn appropriate ways to manage conflict, and reinforcement for violent behavior. Normal coping mechanisms may not be learned or may become impaired, leading to violence as the ultimate resource. Saul McLeod buttresses the above expression thus:

Individuals that are observed are called models. In society, children are surrounded by many influential models, such as parents within the family, characters on children's TV, friends within their peer group and teachers at school. These models provide examples of behavior to observe and imitate, e.g. masculine and feminine, pro and anti-social etc. Children pay attention to some of these people (models) and encode their behavior. At a later time they may imitate (i.e. copy) the behavior they have observed. They may do this regardless of whether the behavior is 'gender appropriate' or not.(12)

In tune with this line of argument, one can infer that violence is a learned behaviour and can be precipitated by different factors. 
Another theory on which this thesis is anchored is the Powercontrol wheel propounded by Duluth. The Power -control Wheel is commonly used by both advocates and researchers to assert that the motive of a perpetrator of domestic is to gain power and control over the subordinate (Pence 24). The Power and Control Wheel places power and control at its core with eight spokes emanating from it and physical violence as the outer wheel holding everything together. According to the most common explanation of the wheel, each spoke represents a tool or type of an external social power resource the barterer can use to exercise dominance over his/her intimate partner. With few exceptions, baterers attempt to cut women off from other people, places, ideas and resources that would help them understand what is happening to them (Pence 15). If successful, this use of power-over collapses the woman's boundaries of self-definition, autonomy, and personhood.

According to Johnson P, "It is not surprising that the institution of gender, in which male domination is a central element, is implicated in the structure of intimate terrorism, which is about coercive control. In contrast, situational couple violence, which is the most common type of partner violence, does not involve an attempt on the part of one partner to gain general control over the other, and by some criteria it appears to be more gender-symmetric. The violence is situationally-provoked, as the tensions or emotions of a particular encounter lead one or both of the partners to resort to violence. Intimate relationships inevitably involve conflicts, and in some relationships one or more of those conflicts turn into arguments that escalate into violence. These theories have been employed as frameworks to interrogate this study. 


\section{Gender Domination and Domestic Violence in Two Nigerian Video Films}

Synopsis of Damage directed by Moses Inwang: A prominent married couple Taiwo and Sarah played by Uche Jombo and Kalu Ikeagu respectively, have a life that is marred by domestic violence. When things are going well, their relationship is blissful, but when it is going badly, it is hellish. On one occasion the husband surprises his wife by spelling out I love you with petals by their swimming pool however the next minute they are engaged in vicious and violent fighting. Quick tempered Taiwo appeases his wife by buying her gifts after fights. Their home life affects their children in the worst way. Their son is violent at school and their daughter is withdrawn to the point of muteness, her own way of protesting, but the couple refuses to see that the violent nature of their relationship is responsible until it is too late.

Analysis of Damage: The film narrative portrayed abuse in marriage using high level of domestic violence, incessant battering and acts of violence. Taiwo, the husband to Sarah is very temperamental and believes in the patriarchal system which makes him the man of the house whose authority and words supersede his wife's. Again, he always gets very angry at the slightest provocation and ends up beating his wife. The film portrays Taiwo as psychologically imbalanced which leads to his battering and often draging his wife down the stairs, but once he is calm and realizes his actions or wants something from his wife, he appologizes. The incessant quarrels and fights obviously affected their children negatively because it was established that their son Junior was in the habit of settling every argument with a fight. Also the fights affected their daughter so badly that she shrank into 
herself and stopped communicating with them in words rather she preferred writing a note to tell them her wants. And it also culminated into Bisi having psychological trauma such that when she sees a street fight she imaginatively replaces the fighters with her parents (Taiwo and Sarah). These reactions go to buttress the centrality of the postulations of the Social learning theory to the live experiences of the characters.

Sarah represents the modern African woman who chooses to fight against subjugation by the men. She refuses being relegated to the position of house wife which made her to get employment in her father's company and even buy a car for herself. Her status as a working- class lady showcases a society where the place of women is not just the kitchen, but the doorsteps of survival, depending on what the survival appears to be eventually; where the do-or-die battle ends invariably without a possible female emancipation. She often disagrees with her husband. Consequently during their fights she often frees herself from the grips of her husband to hit him with objects around the house that are within her reach. It is obvious that she does not pay much attention to her children though she appears to make attempts to ensure the wellbeing of her daughter. She displays similar temperaments as her husband, though not as violently and this makes her unable to avoid responding rudely to her husband. Thus, her character is always striving for equality with her husband and that often engenders the conflict.

This is seen where she took the decision of bringing in a psychologist without the knowledge of her husband Taiwo. Likewise, in the scene where she signed a cheque for her Husband's sister whom the husband had earlier rejected in anger due to her way of life. Sarah seeing that Taiwo is asking why she should sign a cheque for his sister, instead of explaining, requests 
to know why Taiwo should be going through her things. This action symbolizes that she is equal to her husband and has the same authority as the man. Taiwo and Sarah's incessant fight resulted in the psychological imbalance of their daughter and the replacement of images in her mind which finally resulted in to the daughter's death with a scissors being plunged into her stomach. Thus the technique used in showcasing her psychological imbalance is the use of blured clips of images of her parents fighting. This indicates that she is worried about her parents attitudes.

\section{Synopsis of $M r \& M r s$ directed by Ikechukwu Onyeka}

$\mathrm{Mr}$ and Mrs, is a movie that vividly captures the realities of gender discrimination, domestic abuse of women and gender role stereotyping in a male-dominated social order. It x-rays the abuse of marriage in a patriarchal society. The narrative presented two homes with contrasting spouses. Ken Abbah (Benjamin Joseph) is chauvinistic in nature. And he is a business tycoon married to Sussan Abbah (Nse Ikpe Etim), a lawyer, bent on keeping his wife at home as a full time housewife. Being adequately exposed as a lawyer with a Master's degree, Susan thinks she is been subjugated and kept as a prisoner in her matrimonial home. It appears that the more she endeavoured to show her husband love and keep him happy the more the husband (Ken Abbah) kept treating her as a house wife. In addition to doing all the house chores, she is also used as a sex object by the husband, often demanding sex in the bathroom.

Despite her complaints the husband keeps adamant. Then she discovers that he is keeping female friends and seeks advice from a lawyer -friend who tells her to observe when the husband is in the right mood to dialogue with him on her feelings and what 
she wants. She does that and it results to a serious argument, fight and divorce. The couple though divorced, are to live under a common roof pending the conclusion of the gubernatorial election involving Ken's father. This was to forestall public sensations likely to put the election into jeopardy. With the conditional divorce, Susan shakes free of her restrictions and confinement as a wife and acts at will which includes the incessant outings particularly at night and dressing provocatively. Ken in another development brings in another lady to arouse the envy of Susan, but Susan befriends his concubine which defeats Ken's objectives. Ken later battles to save his relationship from total collapse when he realizes his folly. At the denouement of the story, Susan stands her ground on the fact that her being subjected to the kitchen or treated as a maid will no longer work since she has tasted freedom. The couple sorts out their differences and retake their vows in the presence of their friends.

In the parallel plot, Charles and Linda (Thelma Okodua) who are family friends to $\mathrm{Mr}$ and $\mathrm{Mrs}$ Abbah had peculiar problems. Linda works in a bank which keeps her very busy. She goes to work very early before her husband Charles wakes up and comes home very late after her children must have gone to bed. As a result, Linda is unable to take care of her marital responsibilities. Her being absent due to the pressure of her job makes the family dependent on their house girl. After getting the promotion which she had been working hard for, the husband suggests that she transfers to a nearby branch but she refuses. This creates a chance for her husband's infidelity to be given vent as he gets caught in the act (sexual intercourse) with the house girl. At the heat of their crisis, the couple go for counselling to the same lawyer that salvaged the Abbah's mariage. They reach certain compromises and their marriage is revived. 


\section{Analysis of $M r \& M r s$}

The film narrative presented two homes with contrasting spouses. Mr \& Mrs portrayed a good example of domestic violence. Ken's chauvinistic practices in family " $A$ " represents the African patriarchal dominance. And Linda in family "B" represents the western feminist orientation in a family. Whereas Susan in Family "A" represents the African 'Womanist' ideology in which it is believed the African woman is confined to the kitchen and chores of the marital home and thus, they feel subjugated. Susan believes in her role as a wife and mother.

This is acted out in her ability to keep her home in the best conditions possible within her limits while also striving to ensure excellence in her culinary services. Susan is denied her wishes to get a maid and work only because her husband wants her to function merely as a house wife. And she complained about not being able to make her hair which made her look un-kept. This sets the mood of the conflict especially, being a qualified lawyer, this made her feel subjugated. The narrative draws attention to this anomaly using the consequent conflict to teach the desired lessons. Moreover, Mr. Kenneth abused his wife Susan. This is a typical example of patriarchal dominance; Susan undergoes sexual and psychological abuse from her husband because of the socioeconomic and political status of the "Abahs". Find an excerpt below:

Mr. Kenneth Abah walks in saying:

Mr. Kenneth Abah: Your role as my wife does not end in the kitchen, you know?

Mrs. Susan Abah: I have to tidy this up in preparation for tomorrow. 
Mr. Kenneth Abah: And come to bed tired?

Mrs. Susan Abah: Why do you torment me Ken? Your friends come here every Sunday, I feed them, and then, I am left with the dirty dishes.

Mr. Kenneth Abah: But I am not complaining.

Mrs. Susan Abah: But I am. I need help.

Mr. Kenneth Abah: To cook for me? To take care of me?

Mrs. Susan Abah: I'll do the cooking... to tidy up.

Mr. Kenneth Abah: Why do we have to go over this again just because I...

Mrs. Susan Abah: Just because I am tired of being a slave in my own home... just because I have lost my self-esteem. Just because I am no longer the woman I used to be. Look at me, look at my hair, I'm unkempt. We were never like this Ken before your family...

Mr. Kenneth Abah: Don't bring my family into this. You know what, let's go to bed, you are still my wife...

Mrs. Susan Abah: And I still need to have a wash.

Mr. Kenneth Abah: And I can help with that in the bathroom.

\section{Comparative Analysis of Damage and $M r \& M r s$}

The technical attributes of both films are satisfactory. Both films presented contemporary setting and story. The films presented mostly the Western and the African concept of Patriarchy where the men rule or control their female counterpart. They portray the abuse of marriage and high level of domestic violence anchored on the issue of gender balance. In the film Damage, Mr Taiwo Ajayi is temperamental and domineering. He never fails to remind his wife, Sarah, that he is the head of the family anytime he is physically assaulting her. He demands total respect from the family 
and does not want anybody arguing, contradicting or refuting him. To him, being the man of the house means that his opinion is supreme and his orders stand and any perceived opposition from his wife makes him go violent. Likewise, in $M r \& M r s, \mathrm{Mr}$ Kenneth Abbah presents himself as being patriarchal. Here, we see a high level of patriarchal dominance. Kenneth, due to the socioeconomic and political status of the Abah's sees his wife Susan as an object that should be 'seen' and not 'heard'. He relegates the wife (a qualified Lawyer) to a house maid simply because of her poor background as the daughter of a 'washer man'. Hence, he subjects the wife to both sexual and emotional abuse. Apparently, Taiwo and Ken beat-up their wives and maltreated them emotionally, though the women appear handled their emotions differently.

Also in both films, the men appear to love their wives despite their domineering nature and use of violence to get compliance from them and incidentally, any perceived threat to the relationship makes them go through some psychological stress. This is seen for instance in Damage when Taiwo gets home only to be told that his wife's brother Jude has taken his wife and children away. This he couldn't bear. In the same manner when Ken in $M r$ \& Mrs had a feel of what it will be like to lose his wife in a divorce, he made serious efforts to annul the divorce. There is however a strong meeting point in the two films. Both present the Western and African idea of women emancipation. Sarah and Susan symbolize the African 'womanist' concept in Damage and $M r \& M r s$ respectively. This is explicated in the films with Sarah and Susan standing up to their husbands by refusing to be relegated to the kitchen and marginalized. Their resistance to women subjugation goes a long way to show that women can stand up to the men, not necessarily to control them or refute their claims of 
male superiority but to assert their rights as human beings with equal rights. In one family, the wife worked and had no time to take care of the children which made her dependent on the maid, while in the other, the wife worked in her parents firm and did not have much time to concentrate on the kids which made her consult a psychologist.

Ken's character in $M r \& M r s$ is initially portrayed as very strong. His insistence that his wife be home bound in spite of having qualified as a barrister of law later brings spates of conflicts, snow balling into strife and resistance on the part of the wife. In the end ken's stance dropped from a position of strength to that of weakness in order to save his marriage. Likewise, in Damage, Taiwo is portrayed as a very strong and domineering husband who reacts and beat his wife at any slightest provocation, later Taiwo's stance dropped from a position of strength to that of weakness in order to save his daughter's life which failed.

\section{Conclusion}

Many scholars have suggested that domestic violence is a means by which men construct masculinities, however, few studies have explored the specific practices that domestically violent men use to present themselves as masculine actors. Domestic violence continues to be a hideous global social problem. Secular feminists and many egalitarians assert that patriarchy is the ultimate cause of all abuse against women. While there is considerable evidence that patriarchy contributes to much domestic violence, the etymology of domestic violence is far too complex to support any single cause hypothesis. Furthermore, patriarchy and matriarchy must be carefully defined when assessing its impact on abuse, for a wide spectrum of "patriarchy and matriarchy" exists today. All forms of 
patriarchy and matriarchy can and do contribute to domestic violence, it appears that the models of patriarchy and matriarchy which give husbands and wives the greatest levels of power and authority are most likely to stimulate domestic violence.

Film Narratives play significant role in the portrayal of gender domination and domestic violence. This could be in the form of creating frames that serve as social cues for forming expectations about women; or, reinforcing already existing and popular stereotypes about women. To educate and enlighten the society films are presented as better tools for communicating to the viewers using visual codes, myths and conventions and ideologies within a specific culture so as to portray the ills of domestic violence and possible solutions to solving domestic abuse in marital home. The study of Gender domination and Domestic Violence was guided by the desire to correct the misconception and misguided ideology as a general consensus that domestic violence seems to be perpetrated only by the male against their female partners and the counter view that has it that it is gender equivalent.

As part of its findings, the study has established the fact that violence may emanate from either of the gender, be it the male or female who wants to exert power and control over the partner. The Study has revealed that violence occurs when issues unacceptable to either of the partners are being discussed especially if one of the partners is more adept at verbal arguments and the other is desperate to win those arguments, then physical violence becomes an their alternative. Thus, beyond physical demonstration of violence against women, men face psychological violence, just as it has been portrayed in the films under study. Moreover, both the perpetrator and victim feel the effect of the violence and most time it affects the children psychologically. 


\section{Tracie Chima Utoh-Ezeajugh}

\& Ekene Euphemia Anijah

Department of Theatre and Film Studies

Nnamdi Azikiwe University, Awka traciechima@yahoo.co.uk t.utoh-ezeajugh@unizk.edu.ng

\section{Works Cited}

Abayomi, A.A. 'Sociological Implications of Domestic Violence on Children's Development in Nigeria', Journal of African Studies and Development, .6.1 $<$ www.academicjournals.org $>2014 ; 8-13$. Accessed $30^{\text {th }}$ March 2016.

Adebayo AA. and Kolawole T.O.'Domestic Violence and Death: Women as Endangered Gender in Nigeria', American Journal of Sociological Research, Vol 3 No 3. $<$ www.article.sapub.org.com $>2013$; 53-60. Accessed on $31^{\text {st }}$ March 2016.

Adewoye, O.A, Odesanya, Abubakar, and Olorede, "Rise of the 'homo erotica'? Portrayal of women and gender role stereotyping in movies: analysis of two Nigerian movies."Developing Country Studies. 4. 4. London; IISTE, 2014;(103-110).

Agbo, J. "Rethinking the female body language, Image and identity in Nollywood."Journal of Arts and Culture, ed. 10.1. Makurdi; 2012; (128-141).

Animasaun, K, and Animasaun,Y.A "Dimensions of Gender based violence in Africa: the common and the induced."Journal of Research and Development. 1.2, 2013; (62-78) 
Bandura, A. Social Learning Theory. New York: General Learning Press, 1977

Berns, N. Framing the Victim : Domestic Violence, Media, and Social Problems . New York: Aldine de Gruyter, 2004.

Cook, Phillip W. Abused Men: The Hidden Side of Domestic Violence. Westport, CT: Praeger, 1997.

DeKeseredy, W. S.; SchWartz, M. D. "Theoretical and definitional Issues of Violence against Women". In: Ren- zetti, C. M. (eds.). Sourcebook on Violence Against Women. London: Sage, 2011.

Dobash, Russell P."Dobash, R. Emerson; Wilson, Margo; Daly, Martin "39.1:ed.The Myth of Sexual Symmetry in Marital Violence". Social Problems. 1999; 71-91.

Dobash, Russell P. and Dobash, R. Emerson "Women's Violence to Men in Intimate Relationships: Working on a Puzzle". 44.3 ed. British Journal of Criminology. 2004; (324-349).

Ekwuazi, H. "Advertising on television: The television commercial, from premise, through concepts and copy to storyboard \& production." Ibadan: Stirling - Harden Publishers, 1991

Mackinnon, C., 'Sex and Violence; A Perspective in Gender Inequality; Feminist Theories and Politics. Lorber

J. Ed. New York; Roxbury Publishing Company, 1998.

Mulroney and Chan, Men as Victims of Domestic Violence. Australian Domestic \& Family Violence. CleaningHouse, 2005.

Ogundipe, A. "Gender and Culture in Indigenous Films in Nigeria."Gender Activism and Studies in Africa. $<$ www.codesria.com $>2004 ; 88-107$. Accessed on $31^{\text {st }}$ of Mar. 2016 
Okunna Chinyere Stella "Portrayal of Women in Nigerian Home

Video Films: Empowerment or Subjugation?" Africa Media Review Vol. 10. 3.(1996).

Jekayinfa A.A. Types, causes and effects of Gender Based Violence: Challenges for Social Studies Education in Nigeria URL:http://rsh.sasepub.com/content/125/6/272. short Accessed April 10th, 2016.

Mensactivitism, Getting the facts: Research about violence against men URL:http//www.mensactivism.org Assessed April 2, 2016

Moller D. "The Family: Our national Survey for 1990s" 139 ed. Readers Digest, 1991; 31 - 36.

Shaka,F.O, and Uchendu, O.N, 'Gender Representation in Nollywood Video Film Culture' 7 ed. Media Arts The Crab: Journal of Theatre, 2012;1-30

Shaka, F. O. "Modernity and the African Cinema: A Study in Colonial Discourse, Post Modernity, and Modern African Identities." Trenton, NJ: Africa World Press, 2004.

Umukoro J, Okwuowulu, C. "Feminine Image in two Nollywood Films: The Examples of Ije and Mr. and Mrs."12.9. ed. Adeoye A.A, The Performer: Journal of the Performing Arts. Illorin, 2010; (225-234).

\section{Films Cited}

Mr. \& Mrs. Dir. Chinwe Egwuagu. Lagos: Peculiar Communications Productions, 2011.Video film

Damage. Dir. Moses Inwang, Lagos: Uche Jombo / Royal arts academy. 2013.Video cinema 